\title{
correspondence
}

\section{Rights of scientists}

SIR,-You quote the newly published report Scholarly Freedom and Human Rights (24 February, page 671) in stressing the responsibility of learned societies to support oppressed and persecuted scientists by public protests. This is important: hitherto it has usually been argued that only nonscientific channels are permissible for such protests because actions taken by scientific societies would be political demonstrations not consistent with their high scientific aims.

Two points seem to be disregarded in this argument. Firstly, that protests through non-scientific channels emphasise the humanitarian aspect whereas the professional aspect is emphasised only through scientific societies. If a scientist is hindered or restricted in his work and prevented from normal communication and exchange with his colleagues within the international scientific community, not only is his own work impeded but also that of his colleagues and hence scientific progress ir. general. Secondly, that the governments that persecute scientists bring politics into science whereas the scientific societies submit their professional protests just to keep politics out of science.

It has also been argued that international societies should be particularly careful in such matters, whereas national societies might act more freely. However, there are good reasons for the view that an international scientific society is an appropriate channel for appeals and protests when scientists are arbitrarily cut off from the international forum of scientific discussion. The very purpose of an international scientific society is to promote science by fostering international collaboration, communication and exchange among scientists. A national society is involved in professional, educational and advisory activities, and the promotion of international cooperation, which is the main concern of an international society, is of but minor importance. If a member of an international society is prevented from normal communication and exchange with fellow-scientists in other countries, the very purpose of the society is violated and it is the duty of its board to take measures to restore the member to a normal scientific life. Although practical considerations may call for restraint and moderation while acting within an international body, it is important that the principle is made clear. It is the scientific and professional aspect of the matter that should be advanced in this context; political and other arguments should be avoided.

In conclusion, then, it is the duty of scientific societies to speak up officially in defence of oppressed and persecuted scientists.

\section{Gosta Wranglen}

Royal Institute of Technology, Stockholm, Sweden

\section{The Tacoma Bridge collapse}

SIR,--Dr Henry Chilver (10 February, page 494) reviewed a number of accidents and attempted to categorise them by making use of a 'triangle of failures'. The failure of the Tacoma Bridge in 1940 lies in Chilver's diagram midway between 'unknown environmental forces' and 'unpredictable behaviour" and he says that "The cause of the accident was an inadequate understanding of the interaction of the structure with its environment, leading to large oscillations of the bridge. The resulting behaviour was unpredictable at the time ...". There were however indications in information available at that time, but not collated then, that a failure would occur and that the mode of failure was not new. The figure shows variation of span length, $L$, of a suspension bridge, with the year of building. Also shown are corresponding values of the ratio of girder depth, $d$, to span length (some examples are missing because records are incomplete); this parameter is a rough measure of the stiffness of the girder against vertical loads from wind or traffic. In the 19th century, bridges were designed on an intuitive basis and several were destroyed or damaged by winds. In one or two instances, eye witness reports were recorded and these bear remarkable similarity to the observations recorded on film during the collapse at Tacoma. The earlier collapses consistently occurred whenever $d / L$ was less than approximately 0.006 .

At the turn of the century a new theory was developed which seemingly gave mathematical rigour to the design of the deck girder. This theory considered only static wind pressure loading but, for the heavy, deep girders then currently fashionable, it proved very successful and no dynamic behaviour was observed. During the next thirty years several suspension bridges were built and, with the confidence instilled in the designers by the availability of the theory, there was a trend to much lighter girders $(d / L)$. Economy, lower traffic loads and aesthetic appeal were the main driving forces in this move. Eventually, as the figure shows, the values of $d / L$ dropped below 0.006 and wind induced oscillations were observed in a number of bridges, although only the Tacoma Bridge actually collapsed. After that deck girders were made stiffer, but the pattern of development was quickly re-established. (This time, however, the critical value of $d / L$ has been safely reduced because of the use of wind-tunnel testing in conjunction with the design calculations).

Had proper records been kept of trends in bridge design, and had engineers been made aware of earlier windinduced failures, a warning would have been sounded on the dangers of using the analysis for very light deck girders. We have shown that the failures of other bridges of different types could also have been avoided if records had been kept of design trends and minor accidents preceding the major event had been adequately investigated. Similar trends have been noted in structures other than bridges. We suggest the need for a facility to gather and process information on which to base the direction of research on structural behaviour.
A. C. Walker
P. G. SrBLy

Department of Civil Engineering, University College, London

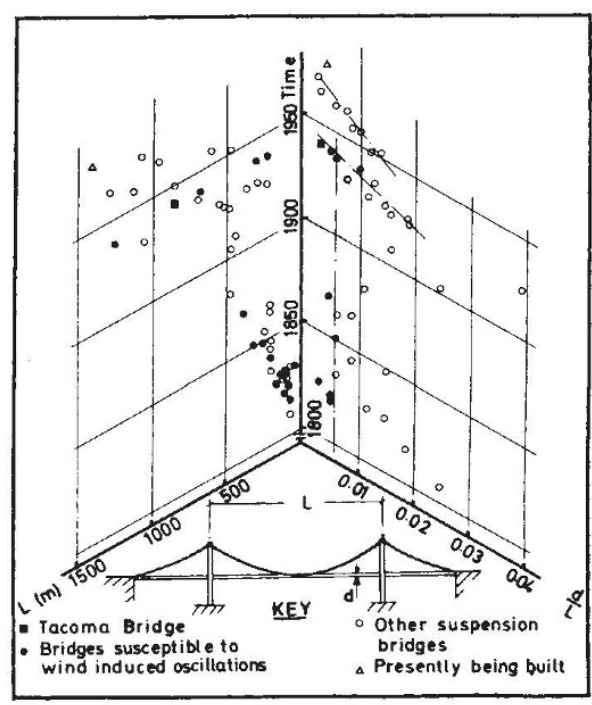

